Research Paper

\title{
Lysophosphatidic acid stimulates epithelial to mesenchymal transition marker Slug/Snail2 in ovarian cancer cells via Gai2, Src, and HIF1a signaling nexus
}

\author{
Ji Hee Ha ${ }^{1,2}$, Jeremy D. Ward2, Rangasudhagar Radhakrishnan', Muralidharan \\ Jayaraman ${ }^{1,2}$, Yong Sang Song ${ }^{3}$, Danny N. Dhanasekaran ${ }^{1,2}$ \\ ${ }^{1}$ Stephenson Cancer Center, The University of Oklahoma Health Sciences Center, Oklahoma City, Oklahoma, USA \\ ${ }^{2}$ Department of Cell Biology, The University of Oklahoma Health Sciences Center, Oklahoma City, Oklahoma, USA \\ ${ }^{3}$ Cancer Research Institute, Seoul National University, Seoul, Korea
}

Correspondence to: Danny N. Dhanasekaran, email: danny-dhanasekaran@ouhsc.edu

Keywords: ovarian cancer, EMT, LPA, HIF1 1 , metastasis

Received: February 19, 2016

Accepted: April 19, 2016

Published: May 07, 2016

\section{ABSTRACT}

Recent studies have identified a critical role for lysophosphatidic acid (LPA) in the progression of ovarian cancer. Using a transcription factor activation reporter array, which analyzes 45 distinct transcription factors, it has been observed that LPA observed robustly activates the transcription factor hypoxia-induced factor-1a (HIF1a) in SKOV3.ip ovarian cancer cells. HIF1a showed 150-fold increase in its activation profile compared to the untreated control. Validation of the array analysis indicated that LPA stimulates a rapid increase in the levels of HIF1a in ovarian cancer cells, with an observed maximum level of HIF1a-induction by 4 hours. Our report demonstrates that LPA stimulates the increase in HIF1a levels via Gai2. Consistent with the role of HIF1a in epithelial to mesenchymal transition (EMT) of cancer cells, LPA stimulates EMT and associated invasive cell migration along with an increase in the expression levels $\mathrm{N}$-cadherin and Slug/Snail2. Using the expression of Slug/ Snail2 as a marker for EMT, we demonstrate that the inhibition of Gai2, HIF1a or Src attenuates this response. In line with the established role of EMT in promoting invasive cell migration, our data demonstrates that the inhibition of HIF1a with the clinically used HIF1a inhibitor, PX-478, drastically attenuates LPA-stimulates invasive migration of SKOV3.ip cells. Thus, our present study demonstrates that LPA utilizes a Gai2-mediated signaling pathway via Src kinase to stimulate an increase in HIF1a levels and downstream EMT-specific factors such as Slug, leading to invasive migration of ovarian cancer cells.

\section{INTRODUCTION}

Ovarian cancer remains as the most fatal gynecological cancers in the world with a five-year survival rate of only approximately $45 \%$ [1]. This is primarily due to our poor understanding of the disease in addition to the asymptomatic nature of this cancer in the early stages. LPA is known to elicit its diverse cellular responses by stimulating various members of the $\mathrm{G}$ protein families Gi, G12, and Gq [2-6]. Importantly, studies from several laboratories, including ours [7-9], have shown that LPA plays a crucial role in the progression of ovarian cancer [10-12]. Indeed, our lab and others have shown that LPA-mediated signaling stimulates proliferation, migration, and invasion of ovarian cancer cells [5, 7-9, 13]. Increased levels of LPA in the ascites of the ovarian cancer patients and a robust membrane-bound LPA-synthetic machinery quite adjacent to LPA-receptors in ovarian cancer cells raise the concentration of LPA in the tumor microenvironment to micromolar concentrations, which may not allow LPA-receptor antagonist to be used as an effective therapeutic agents. Therefore, defining a signaling node downstream of LPA-receptors has become critical to develop therapeutic strategy for inhibiting LPAmediated oncogenic pathway(s). With this overarching goal, our laboratory as well as others have shown that the 
oncogenic activity stimulated by LPA involves the gep oncogenes $\mathrm{G} \alpha 12$ and $\mathrm{G} \alpha 13$ [14] as well as the putative gip2 oncogene Gai2 [8, 15]. However, the role of these oncogenic $\mathrm{G} \alpha$-subunits in the activation of specific LPAmediated oncogenic responses is far from clear. Therefore, we focused on defining the signaling nodes involved in LPA-mediated activation of a specific transcription factor, if any, which can be correlated with a critical oncogenic response.

HIF $1 \alpha$ has been shown to play a critical role in ovarian cancer malignancy, especially ovarian cancer cells found in the hypoxic conditions of the peritoneal cavity [16-18]. While HIF $1 \alpha$ is rapidly degraded in normoxia, it is rapidly stabilized by hypoxia, thereby promoting its transcriptional activity $[19,20]$. In addition to hypoxia, several growth factors including LPA have been shown to induce the expression/stability of HIF1 $\alpha$ [21-24]. However, the mechanisms by which LPA stimulates the increase in the levels of HIF $1 \alpha$ and its activation are not fully understood.

The activation of HIF $1 \alpha$ involves its dimerization with the constitutively expressed HIF1 $\beta$ [25]. This is followed by the translocation of HIF $1 \alpha$ and HIF $1 \beta$ dimers to the nucleus and subsequent HIF $1 \alpha$ mediated transcription of a multiple genes that can promote angiogenesis, glucose metabolism, cell survival, proliferation, and metastasis in cancer [26]. Importantly, one of the critical oncogenic responses orchestrated by HIF $1 \alpha$ is epithelial-to-mesenchymal transition (EMT) process [27-29] in which the cancer cells switch expression of markers of epithelial cells, such as E-cadherin to mesenchymal markers such as N-cadherin, vimentin, and transcription factors Snail1, Slug (Snail2), ZEB1, ZEB2 and Twist thereby facilitating the invasive migration and metastasis of cancer cells [28, 29]. Cells suppress the expression of proteins such as E-cadherin that allow for cell-to-cell attachment and increase the expression of proteins such as $\mathrm{N}$-cadherin and vimentin that promote cell-detachment and migration. Furthermore, expression of EMT-specific transcription factors has been shown to increase the expression of proteins that can degrade extracellular components, which allow the cancerous cells to invade neighboring tissues [30]. This change in cellular markers characterizes a specific shift in the phenotype of the cancerous cells from being stationary to markedly increased invasive phenotype [28, 29]. Accordingly, EMT has been well recognized as a critical mechanism underlying carcinogenesis, cancer progression, and metastasis. Therefore, identifying pathways that can inhibit EMT are of critical importance for cancer therapy.

In the present study, using a transcription array to identify transcription factors activated by LPA-mediated signaling, we demonstrate that LPA potently stimulates the activation of HIF1 $\alpha$ via a pathway involving Gai2 and Src. We further demonstrate that that the activation of LPA-Gai2-Src-mediated signaling pathway induces EMT in ovarian cancer cells and subsequent invasive migration of ovarian cancer cells that can be inhibited by PX-478, a clinically tested inhibitor of HIF $1 \alpha$. Thus, our current study demonstrates that LPA stimulates a signaling nexus involving Gai2, Src, and HIF $1 \alpha$ to induce EMT and migration of ovarian cancer cells. Furthermore, we show that Gai2 signaling is necessary and sufficient for hypoxia-mediated induction of HIF $1 \alpha$ expression, which has not been shown, to our knowledge, by any previous studies to date.

\section{RESULTS}

\section{LPA stimulates the activity and expression of HIF1 $\alpha$ in ovarian cancer cells}

In order to identify possible mechanism utilized by LPA to drive the progression of ovarian cancer we employed a transcription factor array that can analyze the activation profile of fortyfive different transcription factors. SKOV3.ip cells were stimulated with LPA for 20 minutes along with the appropriate vehicle control and the lysates were subjected to the transcription array analysis. Our results indicated that LPA stimulation activated several transcription factors that have previously been shown to be stimulated by LPA including STAT3 [7, 31, 32] and CREB $[7,33,34]$, thus establishing the functional validity of our array analysis. In addition, we observed that LPA stimulated the activity of HIF $1 \alpha$ by 150 -fold compared to the untreated control cells and its activation far exceeded the activation of any other transcription factor on the array (Figure 1A). In light of the recent findings that HIF1 $\alpha$ plays a critical role of in ovarian cancer progression and malignancy [16-18], we sough to investigate the mechanism by which LPA stimulates the activity of HIF $1 \alpha$. Since the expression levels of HIF $1 \alpha$ correlate with its activation $[25,35,36]$, we first determined the expression levels of HIF $1 \alpha$ following LPA stimulation in a panel of ovarian cancer cells. Our results indicated that LPA stimulated an increase in HIF $1 \alpha$ in three different ovarian cancer cell lines, namely OVCAR5, OVCAR2, and OVCA429 (Figure 1B). Thus, our results establish that the effect of LPA on HIF $1 \alpha$ is cell-line independent. Next, we carried out a time-course analysis for the expression of HIF1 $\alpha$ in SKOV3.ip cells in response to LPA. As shown in Figure 1C, LPA stimulated increase in the levels of HIF $1 \alpha$ could be seen from 60 minutes onwards. Furthermore, it can be observed that the levels of HIF $1 \alpha$ increases with time, reaching the maximum levels by 4 hours. Next, we carried out a dose-response curve with different concentrations of LPA. Our results indicated that LPA stimulated an increase in HIF $1 \alpha$ levels in a dose-dependent manner (Figure 1C). Since the maximal increase of HIF1 $\alpha$ 
could be seen with $10 \mu \mathrm{M}$ LPA by 4 hours, the remainder of the experiments in this study involved the use of $10 \mu \mathrm{M}$ LPA.

\section{LPA signaling to HIF1a involves Gai2}

Next, we sought to identify the downstream G protein that mediates LPA- signaling in this process. Previous studies from us [5, 7-9, 13, 37] and others $[2,38-41]$ have shown that LPA-stimulated oncogenic signaling is transduced by the heterotrimeric $\mathrm{G}$ protein

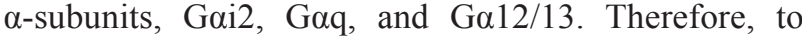

identify the G protein involved in LPA signaling to HIF $1 \alpha$, we stably knocked out the expression of individual $\mathrm{G} \alpha-$ subunits, namely Ga12, Ga13, Gai2, or Gaq in SKOV3. ip cells (Figure 2A) and stimulated these cells with $10 \mu \mathrm{M}$ LPA for 4 hours and monitored the expression levels of HIF1 $\alpha$. Results from such analysis indicated that the Gai2-silenced cells showed a marked decrease in HIF $1 \alpha$ levels compared to the control cells. In contrast, the silencing of $\mathrm{G} \alpha 12, \mathrm{G} \alpha 13$, or Gaq failed to have such an effect (Figure 2B). This was further corroborated using SKOV3.ip cells in which the expression of Gai2 was transiently silenced using Gai2-specific

A

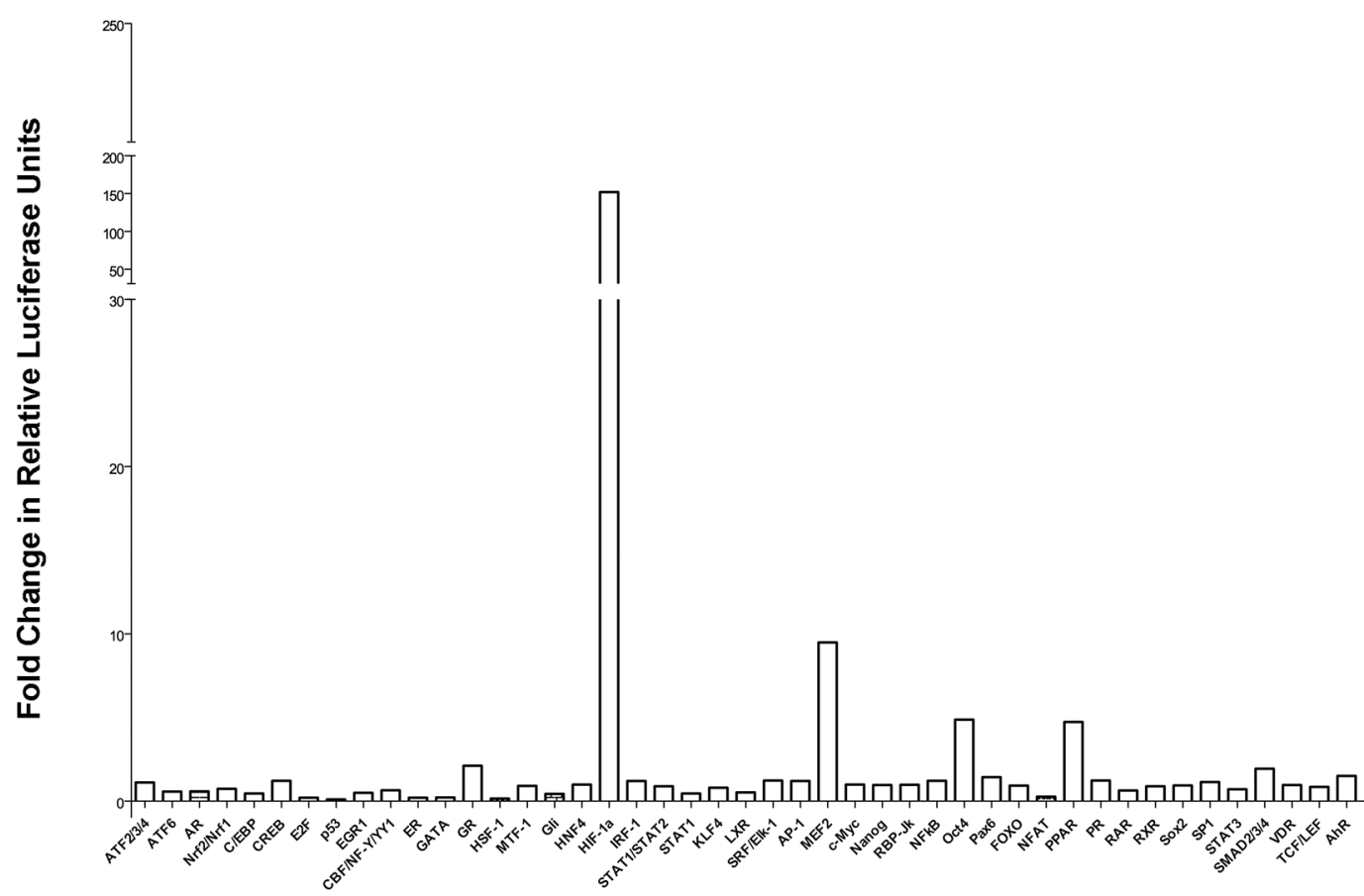

Transcription Factors

B

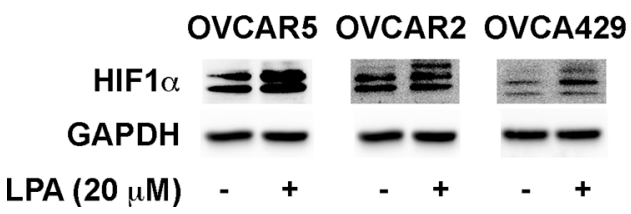

C

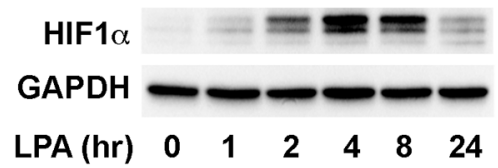

D

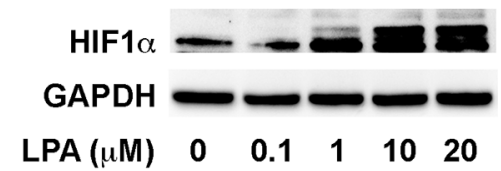

Figure 1: LPA stimulates the activity and the expression of HIF1 $\alpha$. (A) LPA stimulates the activation of HIF $1 \alpha$. SKOV3.ip cells were stimulated with $20 \mu \mathrm{M}$ of LPA for 20 minutes or left untreated in serum-free condition. Activation profiles of 45 different transcription factors were analyzed with a Cignal ${ }^{\mathrm{TM}} 45$-Pathway Reporter Array per manufacturer's protocol. (B) LPA-stimulated increase in HIF1 $\alpha$ is independent of cell types. OVCAR5, OVCAR2, and OVCAR49 cells were serum-starved overnight and then stimulated with $20 \mu \mathrm{M}$ of LPA for 4 hours. The cells were lysed and the level of HIF $1 \alpha$ was analyzed via Western blot. GAPDH was used as a loading control for each lane $(n=3)$. (C) Time-course Analysis of LPA stimulated increase in the levels of HIF1 $\alpha$. SKOV3.IP cells were serum-starved overnight for 16 hours following which they were stimulated with $20 \mu \mathrm{M}$ of LPA for the indicated time points. Lysates were subjected to immunoblot analysis using antibodies to HIF1 $\alpha$. The blot was stripped and re-probed with antibodies to GAPDH to ensure equal loading of proteins in each lane. (D) LPA-stimulated increase in the levels of HIF $1 \alpha$ is dose-dependent. SKOV3.IP cells were serum starved overnight and then stimulated with the different concentrations of LPA for 4 hours. The cells were lysed and subjected to immunoblot analysis using antibodies to HIF $1 \alpha$. The stripped blot was probed with GAPDH-antibodies to monitor equal loading of proteins. 
siRNAs. As shown in Figure 2B, the ability to induce the expression levels of HIF $1 \alpha$ was drastically reduced cells in which the expression of Gai2 was silenced. To further confirm that Gai2 is involved in stimulating an increase in HIF $1 \alpha$ levels, we transiently transfected SKOV3.ip cells with a constitutively active form of Gai2 (Gai2Q205L). The expression of HIF1 $\alpha$ was monitored at $48 \mathrm{hrs}$ following the transient expression of the constitutively active Gai2. As presented in Figure 2C, overexpression of constitutively active Gai2, without any exogenous LPA, resulted in an increase in HIF $1 \alpha$ levels, suggesting that Gai2-signaling is sufficient and responsible for mediating the effect of LPA in increasing the levels of HIF $1 \alpha$ levels in ovarian cancer cells.

\section{LPA induces EMT in ovarian cancer cells}

It has been well established that the induction of HIF $1 \alpha$ expression and its subsequent dimerization with HIF $1 \beta$ to function as a transcription factor in hypoxic conditions is involved in EMT and migration of many different cancer cell types [25, 27, 42]. Taken together with the observation that LPA stimulates HIF $1 \alpha$, it can be surmised that the activation of HIF $1 \alpha$ by LPA could promote EMT in ovarian cancer cells. Therefore, we tested whether LPA could stimulate EMT in these cells. Likewise, it has also been well established that Slug, a critical EMT-specific transcription factor, can be used as a marker to monitor EMT [43, 44]. In addition, previous studies have shown that HIF $1 \alpha$ can induce the EMT and expression of Slug in many cancer cells [4547]. Therefore, we monitored the expression of Slug in response to LPA in ovarian cancer cells to test if LPA activated Slug and induced EMT in these cells. SKOV3. ip cells were stimulated with increasing doses of LPA for 4 hours and the expression levels of HIF1 $\alpha$ and Slug were monitored by immunoblot analysis from the lysates derived from these cells. As shown in Figure 3A, the expression of HIF $1 \alpha$ as well as Slug increased in these cells in a dose-dependent manner. Next, we sought to confirm that the increased expression of HIF $1 \alpha$ and Slug by LPA leads to an increased activation of HIF $1 \alpha$ and Slug. Since activated HIF1 $\alpha$ and Slug translocates to nucleus, the nuclear levels of HIF $1 \alpha$ and Slug are often used as indices of their activation status [48, 49]. Accordingly, to assess the activation of HIF $1 \alpha$ and Slug by LPA, we determined the nuclear levels of HIF $1 \alpha$ and Slug. SKOV3.ip cells were stimulated with $20 \mu \mathrm{M}$ LPA or vehicle control for 4 hours, following which the nuclear extracts were isolated from these cells. The levels
A

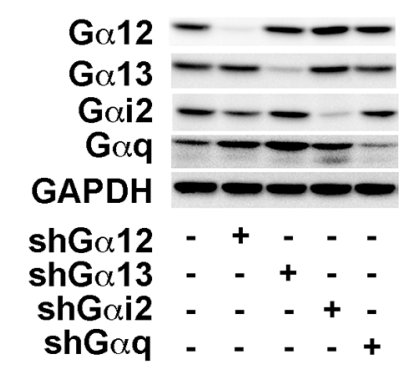

C

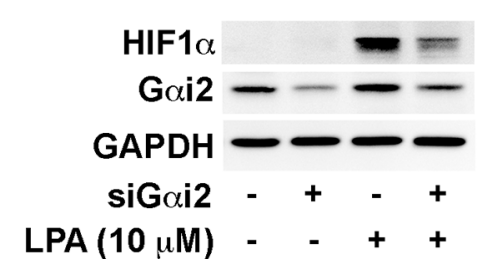

B

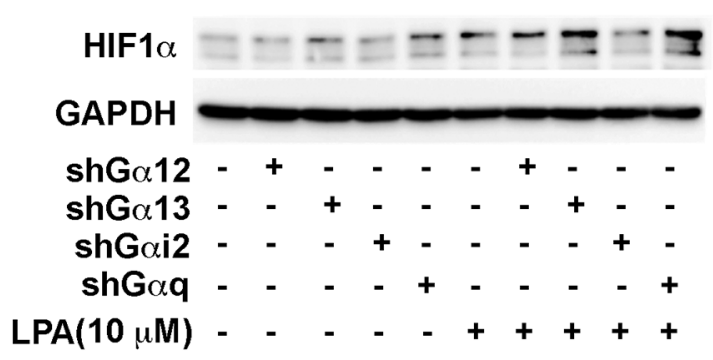

D

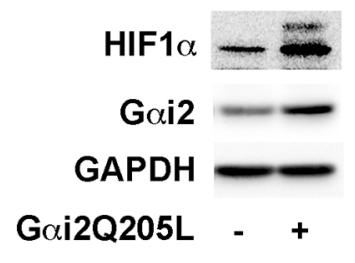

Figure 2: LPA stimulates an increase in the levels of HIF1 $\alpha$ via Gai2. (A) Confirmation of knockdown of G proteins in SKOV3.

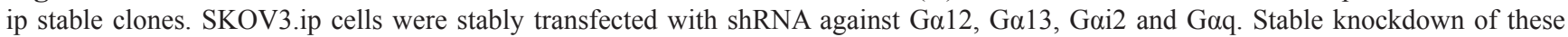
proteins was confirmed by Western blot. (B) Effect of silencing different Ga-subunits on LPA-stilimulated increase in HIF1 $\alpha$ levels. The stable cell lines were serum-starved overnight and then stimulated with $10 \mu \mathrm{M}$ for 4 hours the following day. Immunoblot analysis was carried out with the cell lysates using antibodies to HIF $1 \alpha$ followed by stripping and re-probing with antibodies to GAPDH. (C) Silencing of Gai2 abrogates the LPA-stimulated increase in of HIF $1 \alpha$ levels. Expression of $\mathrm{G}_{\mathrm{i} 2}$ was silenced by siRNA targeting Gai2 or control siRNA for $48 \mathrm{hrs}$. Cells were serum starved for 4 hours and then stimulated with $10 \mu \mathrm{M}$ LPA. After 4 hours, the lysates from the cells were subjected to immunoblot analysis with antibodies to HIF1 $\alpha$. The blot was sequentially stripped and probed with antibodies to Gai2 and GAPDH equal loading. (D) Effect of transient expression of constitutively active mutant of on HIF $1 \alpha$ levels. SKOV3.ip $\left(2 \times 10^{6}\right)$ cells were transiently transfected with either pcDNA3 control vector or pcDNA3 vector encoding Gai2QL, an activated mutant of Gai2. After 48 hours, the cells were lysed and the lysates were subjected to immunoblot analysis using HIF1 $\alpha$-antibodies. The blot was sequentially stripped and re-probed with antibodies to Gai2 and GAPDH to monitor Gai2QL-expression and equal loading respectively $(n=3)$. 
of HIF $1 \alpha$ and Slug in these extracts were monitored by immunoblot analysis. Results indicated that the treatment of ovarian cancer cells with $10 \mu \mathrm{M}$ LPA led to a dramatic increase of HIF $1 \alpha$ and Slug in the nucleus of these cells, thus pointing to the strong activation of these transcription factors by LPA (Figure 3B. To establish that the observed effects of LPA is not cell type-dependent, we examined the ability of LPA to induce the expression of Slug in three different ovarian cancer cells lines. As shown in Figure $3 \mathrm{C}$, stimulation with $20 \mu \mathrm{M}$ of LPA induced Slug expression in all the tested ovarian cancer cell lines: OVCAR3 and OVCAR5 (representing high-grade serous ovarian cancer cell lines $[50,51])$ and OVCAR2 cell lines.

\section{LPA induced EMT in ovarian cancer cells is dependent on Gai2 and HIF1 $\alpha$}

Our findings presented above (Figures 1-3) indicating the ability of LPA to stimulate the activation of HIF $1 \alpha$ via Gai2 taken together with the established role of HIF $1 \alpha$ in the regulation of EMT [27-29] point to a signaling paradigm in which the activation of HIF $1 \alpha$ by LPA via Gai2 is involved in induction of EMT in ovarian cancer cells. To validate such a paradigm, we first analyzed whether the silencing of Gai2 abrogates LPA-induced expressions of Slug. In addition to Slug, we monitored the anticipated increased expression of $\mathrm{N}$-cadherin and decreased expression of E-cadherin as additional markers for EMT [28, 29]. As shown in Figure 4A, LPA stimulated an increase in the EMT markers N-cadherin and Slug along with a decrease in E-cadherin. The silencing of Gai2 drastically blunted the ability of LPA to stimulate the increase Slug and N-cadherin as well as its ability to decrease the levels of E-cadherin. The role of Gai2 in this process was further confirmed using the constitutively activated mutant of Gai2. SKOV3.ip cells were transiently transfected with a constitutively active Gai2Q205L and the expression levels of Slug, N-cadherin, and E-cadherin were monitored by immunoblot analysis using the lysates from these transfectants. Consistent with the mediatory role for Gai2 in this process, the expression of Gai2QL dramatically increased Slug levels as well as N-cadherin levels with a concomitant decrease in E-cadherin levels (Figure 4B). Since our data demonstrates LPA-Gai2 signaling axis is involved in the activation of HIF $1 \alpha$ (Figure 2), it can be reasoned that the induction of EMT by LPA through Gai2 involves HIF1 $\alpha$. To establish such a role for HIF $1 \alpha$ in LPA-induced EMT in ovarian cancer cells, we tested whether the silencing of HIF $1 \alpha$ attenuates the expression of EMT markers in these cells.
A

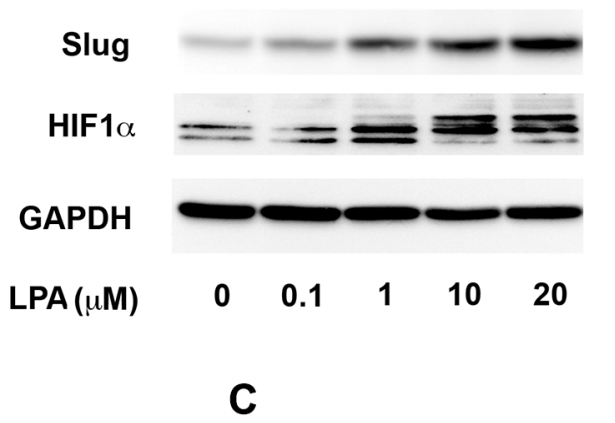

B

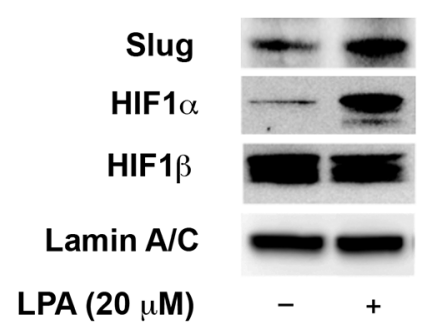

\section{OVCAR3 OVCAR5 OVCAR2}

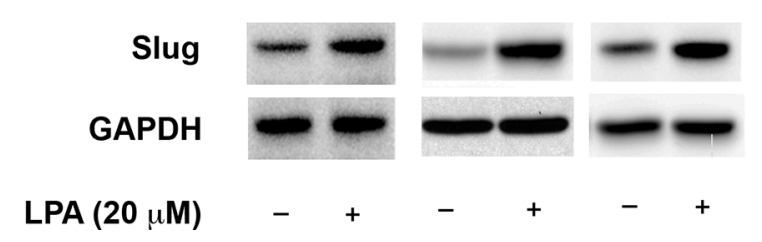

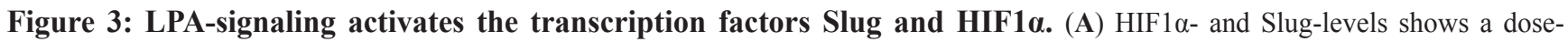
dependent response to LPA stimulation. SKOV3.IP cells were serum starved overnight and then stimulated with the indicated levels of LPA for 4 hours. Cells were lysed and the levels of HIF1 $\alpha$ and Slug in the lysates were analyzed by immunoblot analysis using the respective antibodies. The blot was stripped probed with GAPDH-antibodies to monitor equal loading of proteins. (B) LPA stimulates the nuclear localization of HIF $1 \alpha$ and Slug. SKOV3.IP cells were serum starved overnight and then treated with $20 \mu \mathrm{M}$ of LPA for 4 hours along with untreated control. Nuclear extracts derived from these cells were subjected to immunoblot analysis using antibodies specific to Slug, HIF $1 \alpha$ and HIF1 $\beta$. Levels of Lamin A/C were used as a marker for nuclear compartment and loading control for equal protein loading in each lane. (C) LPA-stimulated increase in the expression of Slug is cell-type independent. OVCAR3, OVCAR5 an OVCAR2 cells were serumstarved overnight and then treated with $20 \mu \mathrm{M}$ of LPA for 4 hours. Expression levels of Slug Lysates derived from these cells were analyzed for the expression levels of Slug by immunoblot analysis using antibodies for Slug. Levels of GAPDH were analyzed in the stripped blot to ensure equal loading of proteins. $(n=3)$. 
The expression of HIF $1 \alpha$ was silenced in SKOV3.ip cell using HIF $1 \alpha$-specific siRNA. The cells were stimulated with LPA for 4 hours and the expression levels of Slug, $\mathrm{N}$-cadherin, and E-cadherin in the lysates were monitored by immunoblot analysis. As shown in Figure 4C, the silencing of HIF $1 \alpha$ in the cells inhibited the increased expression of $\mathrm{N}$-cadherin and Slug along with the decreased expression of E-cadherin, thus validating the conclusion that HIF $1 \alpha$ in LPA-induced EMT of ovarian cancer cells is dependent on HIF $1 \alpha$. Together, these results provide strong evidence that the induction of EMT by LPA involves Gai2-dependent pathway that utilizes downstream transcription factor HIF $1 \alpha$ to mediate the induction of EMT.

\section{LPA enhances hypoxia-induced activation of HIF1 $\alpha$ via a Gai2-dependent pathway}

Ovarian cancer cells are often found in the hypoxic environment of the peritoneal cavity and the core of the primary tumor [52]. A previous report has demonstrated that exogenous LPA stimulation synergistically enhanced hypoxia-induced stabilization of HIF $1 \alpha$ and hypoxia, which in turn, could enhance the oncogenic responsiveness of ovarian cancer cells to LPA [52]. However, the signaling mechanism and the role of $\mathrm{G}$ protein(s) in enhancing
HIF $1 \alpha$ activation remain to be elucidated. Therefore, we set out to determine if LPA signaling could enhance the levels of HIF $1 \alpha$ and subsequent EMT of ovarian cancer cells in a hypoxic environment. To test, ovarian cancer cells incubated in $1 \%$ oxygen environment were stimulated with $10 \mu \mathrm{M}$ of LPA for different lengths of time along with untreated controls. As anticipated, hypoxia alone increased the stabilization of HIF1 $\alpha$ (Figure 5A). However, HIF $1 \alpha$ levels were markedly increased when these cells were stimulated with LPA (Figure 5A). Similar to the results found in normoxic conditions, HIF1 $\alpha$ was maximally stabilized at 4 hours in hypoxic conditions. Next, we examined the effect of hypoxia alone or LPA plus hypoxia on the levels Slug, N-cadherin and E-cadherin. While hypoxic conditions alone induced HIF $1 \alpha$ stabilization and up-regulation of Slug, stimulation of these cells with exogenous LPA dramatically enhanced the up-regulation of Slug and HIF1 $\alpha$ compared to hypoxic condition alone (Figure 5B). Furthermore, exogenous LPA drastically down-regulated the expression of E-cadherin. Overall, these data points to the synergistic role of LPA in enhancing the responsiveness of ovarian cancer cells to hypoxia and inducing EMT. Hypothesizing that the synergistic effect elicited by LPA could involve the Gai2-dependent mechanism, identified in normoxic conditions, we investigated whether the silencing of Gai2
A

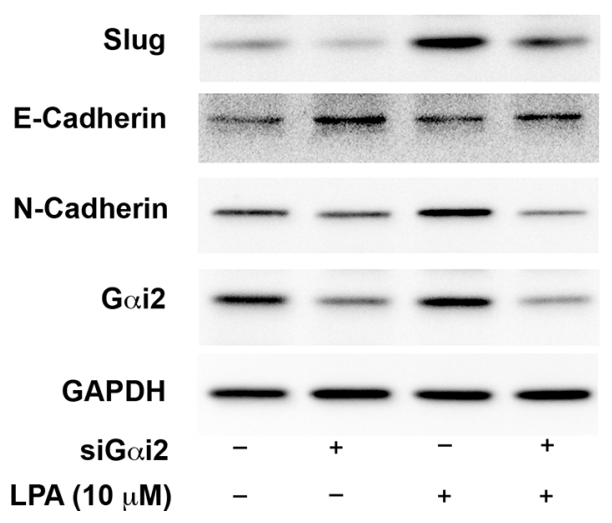

B

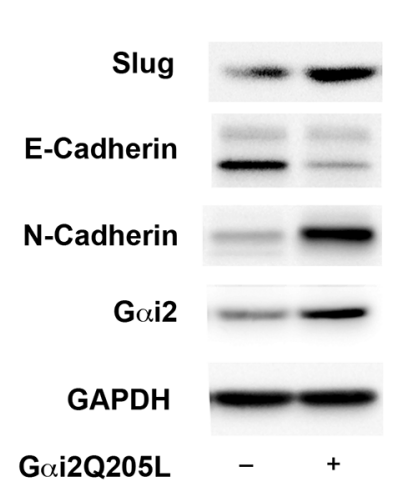

C

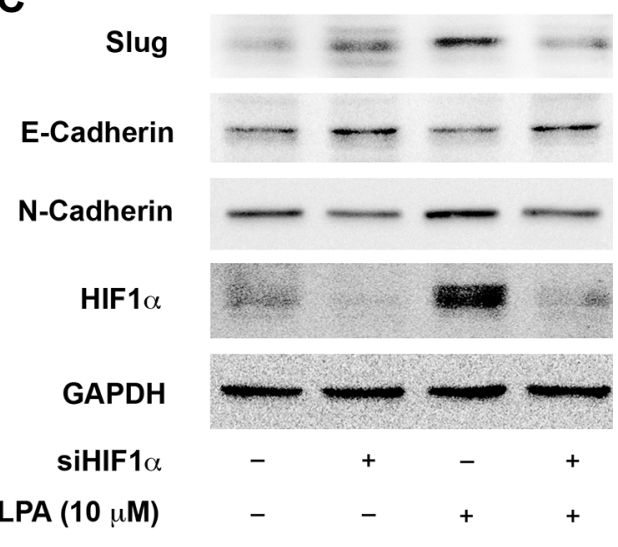

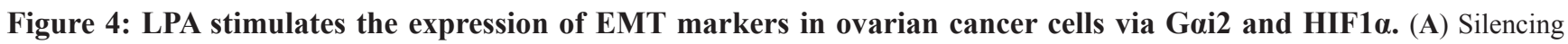
of Gai2 inhibits LPA-mediated changes in EMT markers. SKOV3.IP cells were transiently transfected with siRNA specific for Gai2 or with scrambled control siRNA for 48 hours. The cells were serum-starved for 16 hours and then treated with $20 \mu \mathrm{M}$ of LPA for 4 hours. Lysates from these cells were subjected to immunoblot analysis with antibodies specific to Slug, E-cadherin, and N-cadherin. Silencing of Gai2 was confirmed by probing the blots with an antibody specific for Gai2. The blots were stripped and re-probed with antibodies to GAPDH to monitor equal loading of proteins. (B) Constitutively active Gai2 increases the levels of EMT-markers in ovarian cancer cells. SKOV3.IP $\left(2 \times 10^{6}\right)$ cells were transiently transfected with either pcDNA3 vector control or vector encoding the activated mutant of Gai2, Gai2QL. After 48 hours, the cells were lysed and the lysates were subjected to immunoblot analysis using antibodies to Slug, E-cadherin, and N-cadherin. The blot was stripped and re-probed with antibodies to Gai2 and GAPDH to monitor Gai2QL-expression and equal loading respectively. The experiment was repeated thrice and the results from a typical experiment are presented. (C) Silencing of HIF1 $\alpha$ inhibits LPA-mediated changes in EMT markers. SKOV3.IP cells were transiently transfected with siRNA directed against HIF1 $\alpha$ or with non-targeting siRNA for 48 hours. The cells were serum-starved for 16 hours, following which they were stimulated with $10 \mu \mathrm{M}$ of LPA for 4 hours. Lysates derived from these cells were subjected to immunoblot analysis using antibodies specific Slug, E-cadherin, and $\mathrm{N}$-cadherin. Silencing of HIF $1 \alpha$ was confirmed by using an antibody specific to HIF1 $\alpha$. Levels of GAPDH were assessed to ensure equal loading of each lane. Results are from a typical experiment $(n=3)$. 
abrogates such LPA-stimulated synergistic effect on the hypoxic response involving HIF1 $\alpha$ and Slug. SKOV3.ip cells in which the expression of Gai2 was silenced were incubated in hypoxic condition and stimulated with $10 \mu \mathrm{M}$ LPA along with untreated controls. Our results indicated that the silencing of Gai2 blunted the ability of LPA to enhance the expression of both Slug and HIF1 $\alpha$ in hypoxic conditions (Figure 5C). Remarkably, silencing Gai2 alone, with no exogenous LPA present, led to decreased levels of HIF $1 \alpha$ and Slug compared to controls in hypoxic conditions with no exogenous LPA. This suggests that Gai2 is necessary for the induction of HIF1 $\alpha$ in hypoxic conditions (Figure 5C). Finally, to confirm that Gai2 is needed for hypoxia-induced EMT, both in the presence and absence of exogenous LPA, we analyzed the levels of E-cadherin and N-cadherin in response to LPA in ovarian cancer cells incubated in hypoxia or normoxia. As shown in Figure 5D, silencing of Gai2 inhibited down-regulation of E-cadherin and up-regulation of $\mathrm{N}$-cadherin indicating that Gai2 is necessary for inducing EMT in hypoxic conditions both with and without exogenous LPA.

\section{LPA stimulates the activation of Src via Gai2}

Recent reports from our lab [8, 15] have indicated that Src, via Gai2, is involved in initiating invasive migration of ovarian cancer cells. Additionally, Src has been shown to activate HIF $1 \alpha$ by diverse pathways involving both direct as well as indirect mechanisms [53-55]. Therefore, we investigated if Src is involved in activating HIF $1 \alpha$ and Slug. First, to confirm that Gai2 is needed for the activation of Src by LPA, we transiently silenced Gai2 in these cells and stimulated with $10 \mu \mathrm{M}$ LPA. Activation of Src was monitored by

A

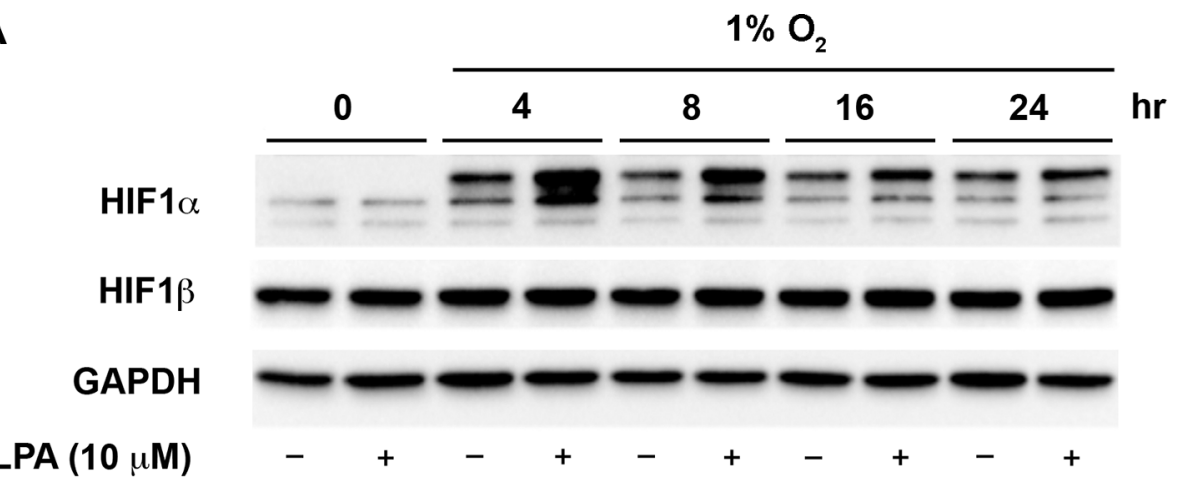

B

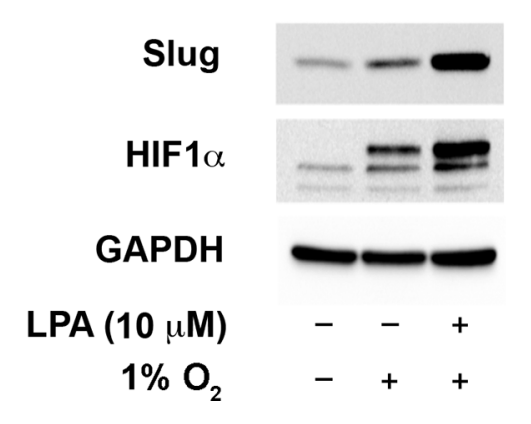

C

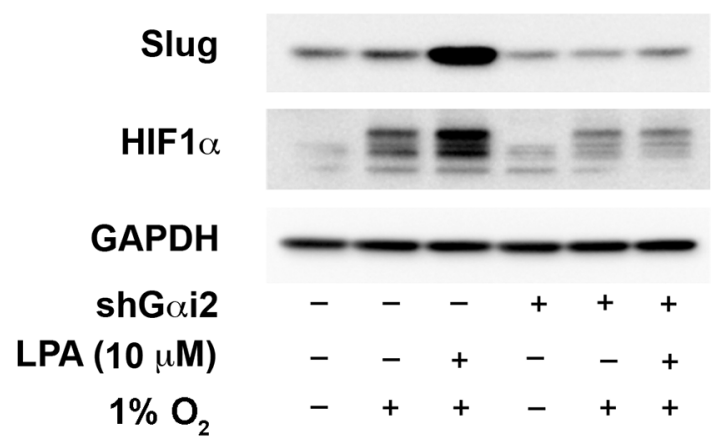

Figure 5: Gai2 stimulates an increase in the levels of HIF1 $\alpha$ in hypoxia. (A) LPA enhances the up-regulation of HIF1 $\alpha$ in hypoxia. SKOV3.ip cells were incubated in a hypoxic chamber containing $1 \% \mathrm{O}_{2}$ and stimulated with $20 \mu \mathrm{M}$ of LPA for the indicated lengths of time. Lysates from these cells were analyzed for the levels of HIF $1 \alpha$ by immunoblot analysis using the antibodies to HIF1 $\alpha$. The blot was stripped and probed with antibodies to HIF1 $\beta$ and GAPDH to monitor their respective levels. The levels of GAPDH were used to monitor equal loading of proteins. (B) LPA enhances hypoxia-mediated increase in Slug levels. SKOV3.ip cells were serum-starved overnight. The control group was left in normoxic conditions while the hypoxia and the hypoxia plus LPA-stimulated cells ( $20 \mu \mathrm{M}$ of LPA) were put into the hypoxic chamber $\left(1 \% \mathrm{O}_{2}\right)$ for 4 hours in serum-free medium. Lysates from these cells were subjected to immunoblot analysis with the antibodies to Slug. GAPDH was probed in the stripped blot to ensure equal loading of proteins in each lane (C) Gai2 is required for the increased expression of HIF1 $\alpha$ and Slug in hypoxia. SKOV3.ip cells with either non-sense shRNA or with shRNA that targeted Gai2 were placed in hypoxic chamber along with normoxic control group. Cells under hypoxia were stimulated with $10 \mu \mathrm{M}$ of LPA for 4 hours. Lysates derived from these cells were subjected to immunoblot analysis using antibodies to HIF $1 \alpha$ and Slug. Levels of GAPDH in the stripped blot were monitored to ensure equal loading of the proteins in each lane. Profile from a representative experiment is presented in each panel $(n=3)$. 
the phosphorylation status of Src on tyrosine residue 419 , which has been established as a good indicator of Src activation [8]. As shown in Figure 6A, silencing Gai2 inhibited the activation of Src, indicating that Gai2 is necessary for the activation of Src by LPA. To confirm that Gai2 is sufficient to activate Src, we transiently transfected ovarian cancer cells with constitutively active Gai2, without any exogenous LPA stimulation, and checked the phosphorylation of Tyr-419 of Src. As shown in Figure 6B, constitutively active Gai2 led to the activation of Src indicating the ability of Gai2 to activate Src.

\section{LPA induces EMT of ovarian cancer cells via Gai2 and Src}

Next, we investigated whether Src is involved in activating HIF $1 \alpha$ and Slug. To test SKOV3.ip cells were treated with PP2, an inhibitor of the Src family of kinases, $[53,56]$, or Bosutinib, a clinically used Src inhibitor [57]. These cells were stimulated with LPA and the expression levels of HIF1 $\alpha$ and Slug were monitored. The efficiencies of the inhibitors were monitored by he phosphorylation status of Tyr-419 of Src by immunoblot analysis. As shown in Figure 7A, treatment with PP2 and Bosutinib significantly inhibited the increase in the levels of Slug and HIF $1 \alpha$, suggesting that Src is required for the effect of LPA on HIF1 $\alpha$ - and Slug-levels. Next, we investigated whether Gai2 and Src were involved in the activation of Slug and HIF $1 \alpha$. The translocation of Slug and HIF $1 \alpha$ to the nucleus has been used as an indicator of their respective activation. Therefore, we carried out immunofluorescence microscopic analysis to demonstrate the translocation of
Slug (Figure 7B) and HIF1 $\alpha$ (Figure 6E) to the nucleus. Treatment of SKOV3.ip cells with $10 \mu \mathrm{M}$ of LPA led to translocation of Slug and HIF1 $\alpha$ to the nucleus, indicating the activation of these transcription factors. More importantly, our results demonstrated that the stable knockdown of Gai2 or treatment of cells with either of the Src-inhibitors, PP2 or Bosutinib, significantly reduced the translocation of Slug (Figure 6D) and HIF1 $\alpha$ (Figure 7B) to the nucleus in reponse to LPA. Together, these results indicate that LPA stimulates Gai2, which then utilizes Src to activate both Slug and HIF1 $\alpha$, the mediators of EMT. To demonstrate the role of Src in LPA-induced EMT, we utilized immunofluorescence analysis of OVCA432 in response to exogenous LPA. OVCA432 cells have previously been shown to be a good model system for studying EMT in ovarian cancer cells due to fact that these cells express high levels of E-cadherin and have more of an epithelial phenotype compared to other ovarian cancer cell lines [58]. As shown in Figure 7A, OVCA432 cells in serum-free media demonstrated a distinct epithelial phenotype with strong E-cadherin staining between the cells. Conversely, treatment of OVCA432 cells with LPA overnight significantly decreased the overall expression levels of E-cadherin (Figure 7A, middle panel). In addition a drastic reduction in the presence of E-cadherin levels in cellular junctions could be observed in these cells. Interestingly, treatment of OVCA432 cells with Bosutinib drastically reduced the ability of LPA to down-regulate E-cadherin localization in inter-cellular junctions as well as its overall expression, indicating that the blockade of Src activation prevented LPA-induced EMT and that Src is needed for induction of EMT of ovarian cancer cells.
A

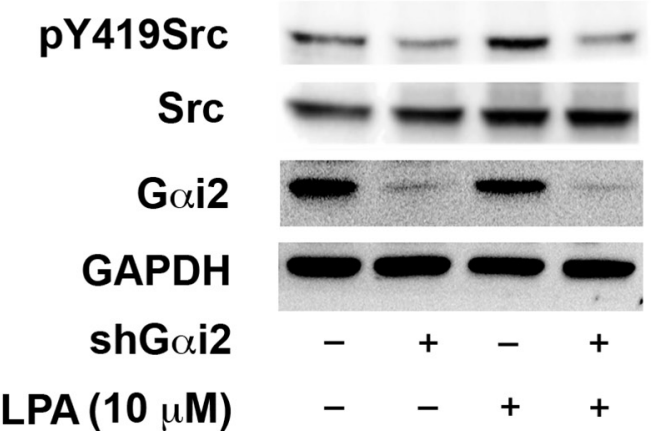

B

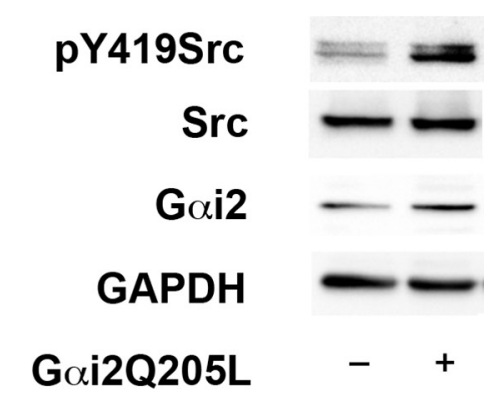

Figure 6: LPA stimulates the activation of Src via Gai2. (A) LPA-mediated activation of Src involves Gai2. SKOV3.ip cells were transiently transfected with either nonsense shRNA or shRNA that targeted Gai2. After 24 hours, the transfected cells were serum starved for 16 hours and treated with $10 \mu \mathrm{M}$ of LPA for 20 minutes along with untreated control groups. Lysates were subjected to immunoblot analysis using antibodies specific to Src phosphorylated on Tyr-419. The blot was stripped and probed for total Src to monitor expression levels and equal loading of proteins. A parallel blot was used to monitor for the silencing of Gai2 using antibodies specific to Gai2. The blot was stripped and re-probed with antibodies specific to GAPDH to monitor equal loading of proteins. (B) Constitutively activated Gai2 stimulates Src. SKOV3.ip $\left(2 \times 10^{6}\right)$ cells were transiently transfected with either vector control or with constitutively active Gai2QL. After 48 hours, the transfectants were lysed and subjected to immunoblot analysis with antibodies specific to tyrosine-419 phosphorylated Src. The blot was stripped and re-probed for total Src. Expression of constitutively active Gai2 was confirmed with antibodies specific to Gai2. The blots were stripped and re-probed with antibodies to GAPDH to monitor equal loading of proteins. Presented results are from a typical experiment $(n=3)$. 


\section{Inhibition of HIF1 $\alpha$ attenuates LPA-induced EMT and cell migration}

Since EMT has been shown to promote invasive migration of cancer cells [28, 59], our results would suggest that the stimulation of HIF $1 \alpha$ by LPA is required for such invasive migration of ovarian cancer cells. It has been shown that PX-478, a clinically used inhibitor of HIF $1 \alpha$, attenuates the activity of HIF $1 \alpha$ by lowering its expression levels [60, 61]. Therefore, we tested whether LPA-stimulated invasive migration of ovarian cancer cells could be attenuated by the inhibition of HIF $1 \alpha$ by PX-478. As shown in Figure 7, LPA potently stimulated the invasive migration of SKOV3.ip cells. However, treating these cells with the escalating doses of PX-478 led to a concentration-dependent inhibition of invasive migration (Figure $8 \mathrm{~A}$ and $8 \mathrm{~B}$ ). Even at the lowest tested dose of $25 \mu \mathrm{M}$ concentration at which the PX-478 markedly reduced the cellular levels of HIF $1 \alpha$ (Figure 8C) -, PX-478 attenuated the invasive migration of SKOV3.ip cells (Figure 8A and 8B). Together, our findings establish the functional role for LPA-Gai2Src stimulated HIF1 $\alpha$ in promoting EMT phenotype in ovarian cancer cells involving the overexpression of Slug and increased invasive migration.

\section{DISCUSSION}

Previously, we have shown the critical role of LPA in promoting cell proliferation and migration in ovarian cancer cells $[7-9,15]$ in addition to establishing the role

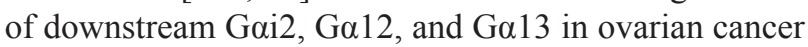
xenograft growth in vivo [14]. In the present study, we demonstrate the role of LPA in the potent activation of HIF $1 \alpha$ in ovarian cancer cells. Using a transcription factor reporter array, we show that LPA stimulates the activation of HIF $1 \alpha$ by 150 -fold within 20 minutes (Figure 1). Further analysis of the underlying mechanism indicates that the activation of HIF1 $\alpha$ by LPA involves Gai2-dependent signaling mechanism (Figure 2) that
A

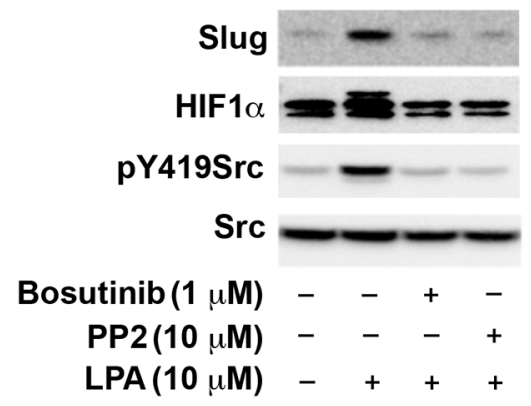

C
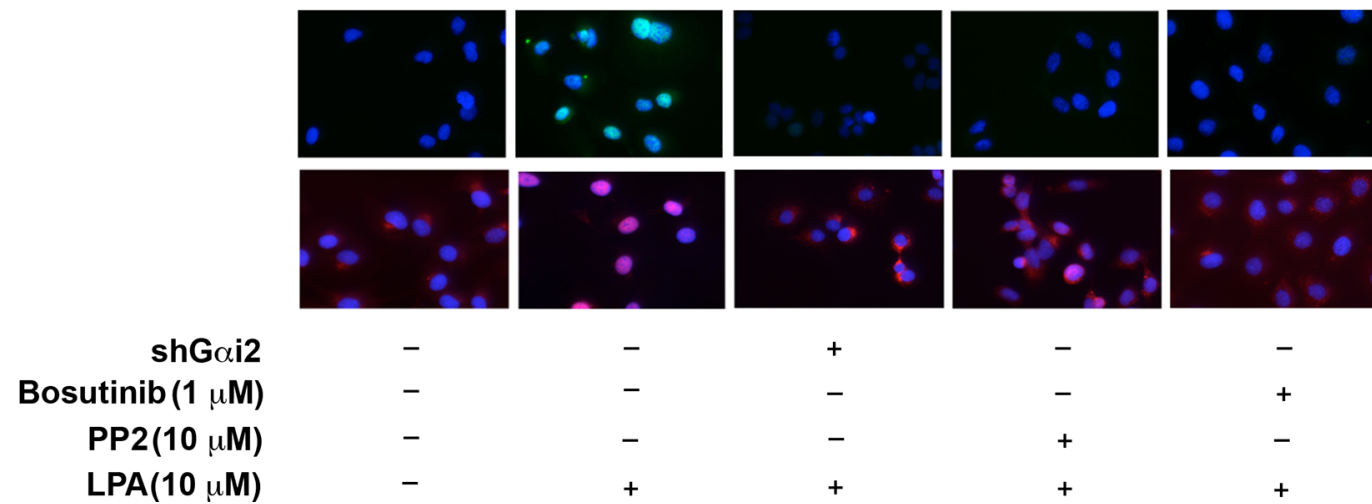

Slug

DAPI

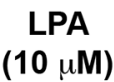

LPA $(10 \mu M)$

Bosutinib (1 $\mu \mathrm{M}$ )
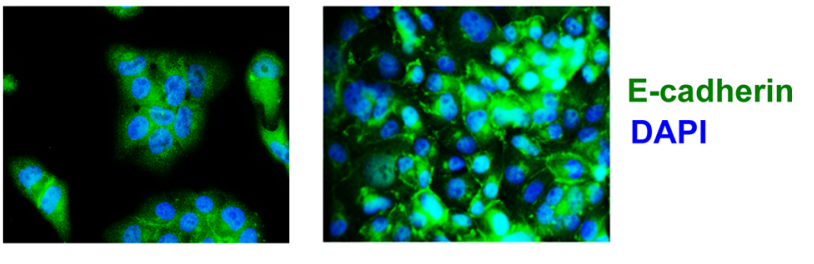

Untreated

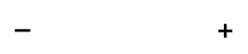

$-$

$-$

$+$
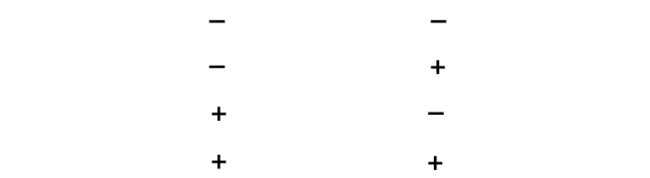

Figure 7: Src is required for the expression and activation of HiF1 $\alpha$ and Slug. (A) Src is required for LPA-mediated increase in the levels of HIF $1 \alpha$ and Slug. SKOV3.ip cells were stimulated with $10 \mu \mathrm{M}$ LPA with or without the incubation with $10 \mu \mathrm{M}$ PP2 or $1 \mu \mathrm{M}$ Bosutinib for 4 hours. Lysates from these cells were subjected to immunoblot analysis using antibodies to HIF1 $\alpha$, Slug, pY419 Src and total-Src. (B) Knockdown of Gai2 or inhibition of Src ablates LPA-stimulated activation of HIF1 $\alpha$ and Slug. Parental SKOV3.ip cells, SKOV3.ip cells in which Gai2 using specific shRNA, SKOV3.ip cells treated with $10 \mu \mathrm{M}$ PP2, or SKOV3.ip cells treated with $10 \mu \mathrm{M}$ Bosutinib were stimulated with $10 \mu \mathrm{M}$ LPA for 4 hours along with the unstimulated control. Cells were stained with an antibody against Slug or HIF $1 \alpha$ and counterstained with DAPI. (C) Inhibition of Src attenuates LPA-induced EMT. OVCA432 cells were stimulated with $10 \mu \mathrm{M}$ LPA for 4 hours or pre-treated $1 \mu \mathrm{M}$ Bosutinib prior to stimulation with $10 \mu \mathrm{M}$ LPA for 4 hours along with untreated control group. At 4 hours cells were stained with an antibody against E-cadherin and counterstained with DAPI $(n=3)$. 
can be correlated with the increased expression of Snail, which is involved in promoting the transcriptional activation of EMT-specific genes (Figures 3 and 4). Our results further demonstrate that the presence of LPA synergistically increases the expression levels of HIF $1 \alpha$ through a Gai2-dependent signaling pathway in hypoxic conditions, such as those found in the ascites fluid of ovarian cancer patients. In this context, we demonstrate here that silencing Gai2 alone, completely of abrogates hypoxia-induced expression of HIF $1 \alpha$ even in the absence of exogenous LPA. These results indicate that Gai2 is required for the hypoxia-induced expression of HIF $1 \alpha$ in ovarian cancer cells (Figure 5). Interrogating further, we establish that Gai2-dependent signaling involves Src to activate HIF1 $\alpha$ (Figure 6). LPA-stimulated signaling nexus involving Gai2 and Src, thus formed, induces
EMT in ovarian cancer cells as indicated by the nuclear translocation of Slug and up-regulation of N-cadherin expression levels and loss of E-cadherin between cells (Figure 7). Finally, we demonstrate that the inhibition of this pathway using PX-478, a HIF1 $\alpha$ inhibitor, drastically decreases the migration of ovarian cancer cells (Figure 8). Thus, Our results presented here demonstrate for the first time that LPA signaling in normoxic conditions activates a Gai2-Src-dependent pathway to up-regulate the transcription factors HIF $1 \alpha$ and Slug and the demonstrated Gai2-Src pathway is critical for induction of EMT by LPA. Importantly, we show that Gai2 is necessary for hypoxia-induced activation of HIF $1 \alpha$ and that LPA, via a Gai2-Src-dependent signaling, synergistically enhances hypoxia-induced activation of HIF $1 \alpha$ and Slug.

A
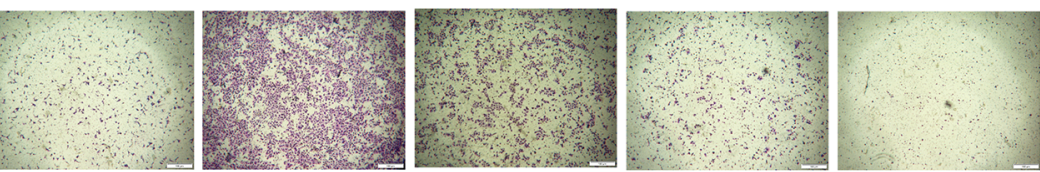

PX-478 $(\mu \mathrm{M})$

0

0

25

50

100

$\operatorname{LPA}(10 \mu \mathrm{M})$

$-$

$+$

$+$

$+$

$+$

B

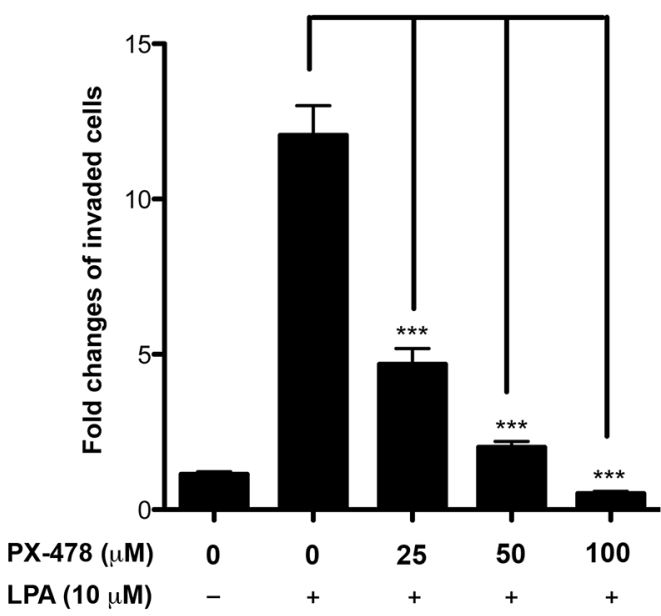

C

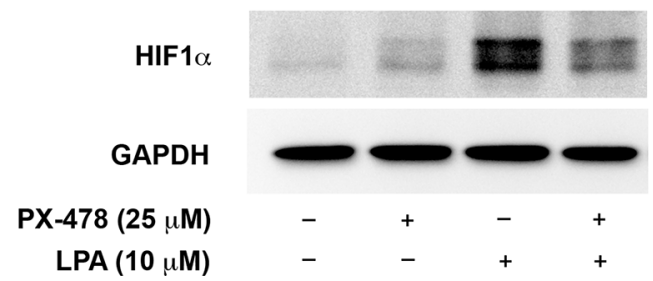

Figure 8: Inhibition of HIF1 $\alpha$ attenuates LPA-induced invasive-migration of ovarian cancer cells. SKOV-ip cells were stimulated with LPA or LPA plus varying concentration of HIF1 $\alpha$ inhibitor PX-478 for 16 hours. A transwell invasive migration was carried out as detailed under Materials and Methods following our previously published procedure. Representative micrograph images of Hemacolor stained invaded cells were obtained at 100× for each of the experimental groups are presented (A). Migrated cells were quantified and presented as fold change over untreated control values (B). Immunoblot analysis with antibodies to HIF $1 \alpha$ was carried out to verify the inhibitory effect of PX-478 on HIF1 $\alpha$ expression levels $(\mathbf{C})$. Representative data from a typical experiment is presented $(n=3$; $* * * p<0.0001)$. 
Previous studies have shown that the levels of HIF $1 \alpha$ is regulated at multiple levels such as the inhibition of degradation of HIF $1 \alpha$, increased translation of HIF $1 \alpha$ mRNA, and enhanced transcription of HIF1 $\alpha$ gene [62]. Although these mechanism are not mutually exclusive, the observation that the effect of LPA on the activation of HIF $1 \alpha$ can be seen by as early as 20 minute, points to the role of LPA in the stabilization of HIF1 $\alpha$ through Gai2. A novel and yet another critical observation reported here is the finding that the stabilization of HIF $1 \alpha$ in hypoxic condition - independent of exogenous LPA treatment is also dependent on Gai2. Previous findings from our laboratory have indicated that LPA-Gai2 signaling could rapidly stimulate Rac via p130Cas/Src dependent pathway [15]. It has also been shown that Src can stimulate an increase in the levels and subsequent activation of HIF1 $\alpha$ involving Rac-stimulated ROS generation via NADPH oxidase [54]. Connecting these two independent observations, our data presented here points to a signaling paradigm in which the signaling by LPA propagates through Gai2 and Src to HIF1 $\alpha$ (Figure 9).

HIF $1 \alpha$ signaling has been linked to EMT and cancer progression. There is voluminous reports that HIF $1 \alpha$ and hypoxic conditions are linked to EMT [27]. Indeed, HIF1 $\alpha$ has been linked to directly up-regulating the expression of Twist [63, 64] and Snail [65]. Similarly, several very recent reports have shown that HIF $1 \alpha$ can induce expression of Slug [45-47]. A recent has shown that knockdown of HIF $1 \alpha$ resulted in decreased mRNA levels of Slug, indicating that HIF $1 \alpha$ is directly or indirectly involved in Slug expression [45]. It has also been shown that Slug is involved in the transcriptional repression of E-cadherin $[66,67]$. In this context, our current study defines the upstream signaling mechanism involving a specific $G$ protein in the activation of HIF $1 \alpha$ and subsequently Slug. Future studies should define the mechanism by which HIF $1 \alpha$ increases the transcription of Slug. Nevertheless, it is clear that HIF $1 \alpha$ and Slug are two transcription factors whose levels are directly increased by LPA via the Gai2Src signaling node. These findings provide evidence that this signaling node can be targeted directly to inhibit expression of Slug and stabilization of HIF1 $\alpha$. Since these two transcription factors have been shown to be important in EMT and drug resistance in a multitude of cancers, our findings underscore the possibility that the pathway we have identified here is directly contributing to ovarian cancer progression and potentially drug-resistance. Recent finding that the expression of Gai2 increases in advanced stage ovarian cancers [68], further points to critical role of Gai2 and the identified pathway as a potential therapeutic signaling node in advanced ovarian cancer. Moreover, besides contributing to cell migration and EMT, it is highly likely that HIF $1 \alpha$ activation via the Gai2-Src pathway is also involved in other effects such as resistance to apoptosis, enhanced glucose uptake, and angiogenesis, all of which have been shown to be critically involved in tumor growth and progression.

Of critical importance, we show here that Gai2 is also necessary for HIF $1 \alpha$ activation independent of exogenous LPA signaling. Thus, there is a distinct possibility that LPA and/or other ligands that utilize Gai2, such as CXCL12, could be responsible for activation

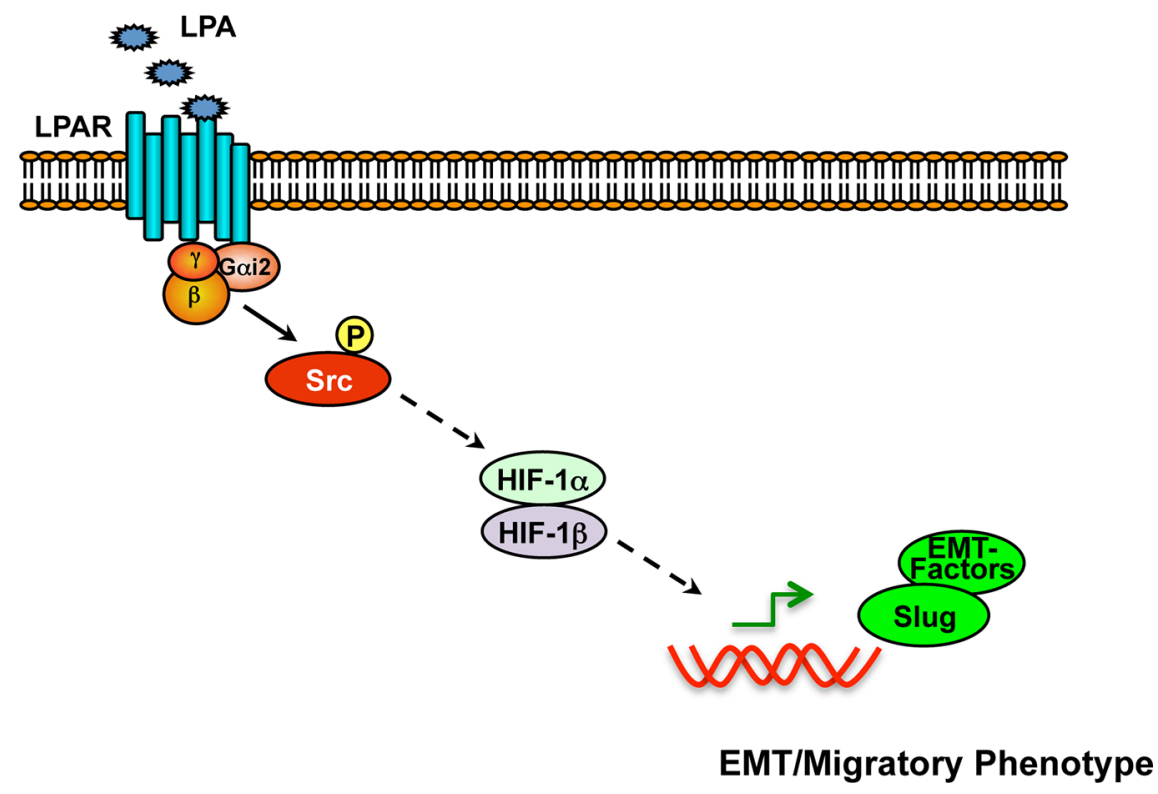

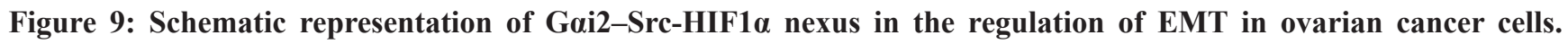
Stimulation of LPA receptors leads to the activation of Gai2 and the subsequent activation of Src, as we have shown previously [8, 15]. Src-dependent signaling, in turn, stimulates the upregulation and activation of HIF $1 \alpha$. HIF $1 \alpha$, once activated, stimulates the expression and resultant activation of Slug and other EMT-specific factors including N-cadherin, thereby promoting EMT and associated invasive migration of cancer cells. 
HIF $1 \alpha$ in hypoxic conditions via autocrine/paracrine signaling. However, this needs to be investigated further. Nonetheless, our report demonstrates that Gai2 and Src are needed for HIF $1 \alpha$ activation in hypoxic conditions, indicating that inhibition of this pathway can suppress hypoxia-induced resistance in ovarian cancer patients. This is also the first report to our knowledge that has shown the importance of LPA-signaling via Gai2 in inducing EMT. Although a recent study reported the ability of LPA to induce EMT via Wnt/ $\beta$-catenin signaling pathways [69], the underlying mechanism was not fully clarified. In this regard, our study presented here firmly establishes the role of Gai2-Src-HIF1 $\alpha$ signaling nexus in promoting LPA-stimulated induction of Slug which is involved in EMT. Finally, this report adds to our previous findings $[8,15]$ that demonstrated the role of Gai2-Srcp130Cas-dependent mechanism in LPA-induced invasivemigration of ovarian cancer cells. It should be noted here that PX-478 has been shown to enhance the antitumor effects of both radio- as well as chemotherapeutic modalities [61, 70-72]. Based on the potent inhibitory effect of PX-478 on HIF1 $\alpha$ levels, one can speculate that the treatment with PX-478 will downregulate the multitudes of HIF1 $\alpha$-regulated genes, including those involved in EMT phenotype such as Slug and resultant ddecrease in the expression of E-cadherins. In this context, our present observation that the clinically relevant dose of PX-478 $(25 \mu \mathrm{M})$ potently inhibits the invasive migration of ovarian cancer cells (Figure 8) further establishes the therapeutic potential of the LPA-Gai-HIF $1 \alpha$ signaling node (Figure 9), especially in HIF $1 \alpha$ overexpressing ovarian cancers.

\section{MATERIALS AND METHODS}

\section{Cells and reagents}

The ovarian cancer cell lines OVCAR2, OVCAR3, OVCAR5 and OVCA432 were kindly provided by Susan K. Murphy (Duke University, Durham, NC). SKOV3. ip1 cells (SKOV3.ip), an in vivo passaged variant of SKOV3 cells established by Yu et al., [73] were kindly provided by Dr. Robert C. Bast (MD Anderson Cancer Center, Houston, TX). OVCAR2, OVCAR3, OVCAR5, OVCA429, OVCA432 and SKOV3.ip cells were maintained in Roswell Park Memorial Institute (RPMI) 1640 media (Mediatech, Manassas, VA) containing 10\% FBS (Gemini Bio-Products, West Sacramento, CA), $50 \mu / \mathrm{mL}$ penicillin, $50 \mathrm{mg} / \mathrm{mL}$ streptomycin (Mediatech, Manassas, VA) at $37^{\circ} \mathrm{C}$ in a $5 \% \mathrm{CO}_{2}$ incubator. For serumstarvation, the media used was RPMI 1640 with $0.1 \%$ BSA (Roche, Indianapolis, IN), $50 \mathrm{U} / \mathrm{mL}$ penicillin and $50 \mathrm{mg} / \mathrm{mL}$ streptomycin (Mediatech). Lysophosphatidic acid (1-oleoyl-2-hydroxy-sn-glycero-3-phosphate) was obtained from Avanti Polar Lipids (Alabaster, AL) and dissolved into $10 \mathrm{mM}$ stock solutions in PBS with $0.1 \%$
BSA and stored at $-80^{\circ} \mathrm{C}$ until use. Non-target control shRNA pLKO.1 vector construct was purchased from Sigma-Aldrich, St. Louis, MO (SHC002) whereas pLKO.1 vector constructs targeting Gai2 (RHS3979-9596925) was purchased from Open Biosystems (Lafayette, CO). The siGENOME Non-targeting siRNA (D-001206-13-05), siGENOME SMARTpool Gai2 (M-003897-00-0005) and HIF1 $\alpha$ (M-004018-05-0005) were purchased from Dharmacon (Lafayette, CO). Peroxidase-conjugated antirabbit IgG was purchased from Promega (Madison, WI), and peroxidase-conjugated anti-mouse was purchased from GE Healthcare (Little Chalfont, UK). E-cadherin antibody was purchased from Santa Cruz Biotechnology (Santa Cruz, CA). HIF1 $\alpha$ antibody was purchased from BD Biosciences (San Jose, CA). Alexa 568 anti-mouse and Alexa 488 anti-rabbit antibodies were purchased from Invitrogen (Eugene, OR). DAPI was purchased from Life Technologies and used at a working concentration of 0.25 $\mu \mathrm{g} / \mathrm{mL}$.

\section{Cell transfection}

All cells were transfected with a Nucleofector II system from Lonza (Allendale, NJ) using the provided transfection protocol for SKOV3 cells as published previously $[8,15]$. SKOV3.ip cells were trypsinized and counted using a Countess automated cell counter (Life Technologies). $2 \times 10^{6}$ cells per transfection cuvette were transfected with either non-targeting siRNA (100 nM), siRNA targeting Gai2 (100 nM), Gai2QL $(2 \mu \mathrm{g})$ or pcDNA3 vector $(2 \mu \mathrm{g})$ as indicated. After transfection, the cells were plated on $60 \mathrm{~mm}$ plates and allowed to adhere overnight. The following day the media was changed and the cells were allowed to grow until the end of the day. The cells were then were re-plated at a density of $5 \times 10^{5}$ cells per $100 \mathrm{~mm}$ plate and allowed to adhere overnight. For stable transfection, SKOV3.ip cells transfected as previously described with shGai2 or control, nonsense shRNA and selected for the expression of shGai2 or the nonsense vector with puromycin [9].

\section{Hypoxia treatment}

Hypoxia treatments $\left(1 \% \mathrm{O}_{2}\right)$ were performed in INVIVO $_{2} 400$ hypoxia workstation (Baker, Sanford, ME). Cells were incubated with $5 \% \mathrm{CO}_{2}$ and $1 \% \mathrm{O}_{2}$ at $37^{\circ} \mathrm{C}$ for the indicated lengths of time. After incubation, cells were collected and western blot analysis was carried out.

\section{Transcription factor reporter assay}

Cignal $^{\mathrm{TM}}$ 45-Pathway Reporter Arrays (Qiagen, CA) was used to screen for different transcription factors upon LPA stimulation of SKOV3.ip ovarian cancer cells. Cells were seeded into wells $\left(50,000\right.$ cells/well) of the Cignal $^{\mathrm{TM}}$ Finder 96-well plates (Qiagen, CA) to transfect the 
reporters into cells via reverse transfection according to manufacturer's protocol. Briefly, reporter DNA constructs resident in each well of the plate were resuspended with $125 \mu \mathrm{l}$ Opti-MEM and complexed with $25 \mu \mathrm{l}$ of Lipofectamine 2000 (ThermoFisher, CA) transfection reagent. Each well is added with $5 \times 10^{4}$ cells suspended $25 \mu$ of Opti-MEM media. Transfection was allowed to happen by incubating the plate for $24 \mathrm{~h}$ at $5 \% \mathrm{CO}_{2}$ and $37^{\circ} \mathrm{C}$. Following transfection, the cells were serum deprived for $16 \mathrm{~h}$ and treated with either vehicle $(0.1 \%$ BSA in PBS) or LPA $(20 \mu \mathrm{M})$ for $20 \mathrm{~min}$. Differential activation of the transcription factors were determined by lysing the cells and measuring the luminescence intensity following the manufacturer's protocol.

\section{Fluorescence imaging}

OVCA432 and SKOV3.ip cells were plated at density of $1 \times 10^{5}$ in 6 -well plates with glass coverslips at the bottom. The cells were allowed to adhere overnight in a $37^{\circ} \mathrm{C}$ incubator with $5 \% \mathrm{CO}_{2}$. The cells were washed $3 \times$ with sterile PBS and then serum-starved for 4 hours. After serum-starvation, the cells were treated with $10 \mu \mathrm{M}$ of LPA for 4 hours. After LPA treatment, the cells were washed with ice-cold PBS one time and then treated with $4 \%$ paraformaldehyde for 15 minutes while rocking. The cells were then washed with PBS $1 \times$ and then stored at $4{ }^{\circ} \mathrm{C}$ until they were stained. All treatment groups were lysed with $0.25 \%$ Triton X-100 for 10 minutes and then washed with PBS $3 \times$. After washing, the coverslips were blocked with $1 \%$ BSA in PBS for 30 minutes at room temperature while rocking. After blocking, the coverslips were washed with PBS $1 \times$. After washing, the primary antibody was applied in $1 \%$-BSA in PBS and rocked for 10 minutes at room temperature. The coverslips were then transferred to $4^{\circ} \mathrm{C}$ and incubated overnight while rocking. The following day the primary antibody was removed and the coverslips were washed $3 \times$ for 5 minutes each. After washing, the coverslips were incubated with fluorescently tagged secondary antibody for 45 minutes at room temperature while rocking and covered with aluminum foil. After incubation with the secondary antibody, the coverslips were washed $1 \times$ with PBS and then stained with DAPI for 5 minutes. The coverslips were then washed $3 \times$ with PBS for 5 minutes each wash and then allowed to dry. Once dry, the coverslips were mounted with ProLong Gold antifade from Life Technologies (Grand Island, NY) on glass slides. The coverslips were allowed to dry overnight at room temperature in the dark and then imaged the following day with a Nikon Eclipse Ni-U (Melville, NY) at $600 \times$.

\section{Collagen-1 transwell migration assay}

The Collagen-1 migratory invasion assay was performed as previously published [8]. Collagen type 1 was coated overnight onto $8-\mathrm{mm}$ pore transwells at $4^{\circ} \mathrm{C}$. The following day, the collagen-coated cell culture inserts containing $5 \times 10^{4} \mathrm{SKOV} 3$.ip cells were suspended in $200 \mu \mathrm{L}$ serum-free media were placed in the well of a 24-well companion plate. Each well contained $500 \mathrm{~mL}$ media containing serum-free media control or serum-free media containing $10 \mu \mathrm{M}$ of LPA. The cells were incubated for 20 hours. Non-migrating cells on the proximal side of the inserts were removed with a cotton swab, and the migrated cells on the distal side of the inserts were fixed and stained with Hemacolor (EMD Chemicals). Images were obtained at $100 \times$ in 5 random fields for each group. The experiments were repeated 3 times. SKOV3.ip cells were transfected with the indicated plasmid (shRNA) and plated into 6-well plates for a total of 48 hours. Twentyfour hours after transfection, the cells were serum starved for an additional 24 hours, trypsinized, counted, and placed into the transwell.

\section{Western blotting}

Immunoblot analysis with the indicated antibodies were carried out following previously published procedures $[8,74]$ and developed with a Kodak Image Station 4000 MM.

\section{Statistical analysis of data}

An unpaired two-tail $t$-test with Welch's correction was performed to determine statistical significance.

\section{Abbreviations}

LPA: lysophosphatidic acid; HIF1: hypoxia-induced factor-1; EMT: epithelial-to-mesenchymal transition.

\section{ACKNOWLEDGMENTS AND FUNDING}

This research was supported by National Institutes of Health grants CA116984, CA123233 (to D.N.D), GM103639 (to D.N.D \& J.H.H) and Priority Research Centers Program (2009-0093820), the BK21 plus program (5256-20140100) through the National Research Foundation of Korea (to Y.S.S). We also thank the Stephenson Cancer Center at the University of Oklahoma, Oklahoma City, OK and an Institutional Development Award (IDeA) from the National Institute of General Medical Sciences of the National Institutes of Health under grant number P20 GM103639 for the fluorescence imaging and immunostaining services. 


\section{CONFLICTS OF INTEREST}

None.

\section{REFERENCES}

1. Siegel R, Ward E, Brawley O, Jemal A. Cancer statistics, 2011: the impact of eliminating socioeconomic and racial disparities on premature cancer deaths. CA Cancer J Clin. 2011; 61:212-236.

2. Bian D, Mahanivong C, Yu J, Frisch SM, Pan ZK, Ye RD, Huang S. The G12/13-RhoA signaling pathway contributes to efficient lysophosphatidic acid-stimulated cell migration. Oncogene. 2006; 25:2234-2244.

3. Bian D, Su S, Mahanivong C, Cheng RK, Han Q, Pan ZK, Sun P, Huang S. Lysophosphatidic Acid Stimulates Ovarian Cancer Cell Migration via a Ras-MEK Kinase 1 Pathway. Cancer Res. 2004; 64:4209-4217.

4. Moolenaar WH, van Meeteren LA, Giepmans BN. The ins and outs of lysophosphatidic acid signaling. Bioessays. 2004; 26:870-881.

5. Radhika V, Hee Ha J, Jayaraman M, Tsim ST, Dhanasekaran N. Mitogenic signaling by lysophosphatidic acid (LPA) involves Galpha12. Oncogene. 2005; 24:4597-4603.

6. Goldsmith ZG, Dhanasekaran DN. G Protein Regulation of MAPK Networks. Oncogene. 2007; 26:3122-3142.

7. Ha JH, Ward JD, Varadarajalu L, Kim SG, Dhanasekaran DN. The gep proto-oncogene Galpha12 mediates LPAstimulated activation of CREB in ovarian cancer cells. Cell Signal. 2014; 26:122-132.

8. Ward JD, Dhanasekaran DN. LPA Stimulates the Phosphorylation of p130Cas via Galphai2 in Ovarian Cancer Cells. Genes Cancer. 2012; 3:578-591. doi: 10.1177/1947601913475360.

9. Goldsmith ZG, Ha JH, Jayaraman M, Dhanasekaran DN. Lysophosphatidic Acid Stimulates the Proliferation of Ovarian Cancer Cells via the gep Proto-Oncogene Galpha. Genes Cancer. 2011; 2:563-575. doi: $10.1177 / 1947601911419362$.

10. Mills GB, Moolenaar WH. The emerging role of lysophosphatidic acid in cancer. Nature reviews Cancer. 2003; 3:582-591.

11. Fang X, Schummer M, Mao M, Yu S, Tabassam FH, Swaby R, Hasegawa Y, Tanyi JL, LaPushin R, Eder A, Jaffe R, Erickson J, Mills GB. Lysophosphatidic acid is a bioactive mediator in ovarian cancer. Biochim Biophys Acta. 2002; 1582:257-264.

12. Bast RC Jr, Hennessy B, Mills GB. The biology of ovarian cancer: new opportunities for translation. Nat Rev Cancer. 2009; 9:415-428.

13. Gardner JA, Ha JH, Jayaraman M, Dhanasekaran DN. The gep proto-oncogene Galpha13 mediates lysophosphatidic acid-mediated migration of pancreatic cancer cells. Pancreas. 2013; 42:819-828.

14. Ha JH, Gomathinayagam R, Yan M, Jayaraman M, Ramesh R, Dhanasekaran DN. Determinant role for the gep oncogenes, Galpha12/13, in ovarian cancer cell proliferation and xenograft tumor growth. Genes Cancer. 2015; 6:356-364. doi: 10.18632/genesandcancer.72.

15. Ward JD, Ha JH, Jayaraman M, Dhanasekaran DN. LPAmediated migration of ovarian cancer cells involves translocalization of Galphai2 to invadopodia and association with Src and beta-pix. Cancer Lett. 2015; 356:382-391.

16. Seeber LM, Horree N, Vooijs MA, Heintz AP, van der Wall E, Verheijen RH, van Diest PJ. The role of hypoxia inducible factor-1alpha in gynecological cancer. Crit Rev Oncol Hematol. 2011; 78:173-184.

17. Lubin J, Markowska A, Knapp P. Factors affecting response of chemotherapy in women with ovarian cancer. Eur J Gynaecol Oncol. 2012; 33:644-647.

18. Jin Y, Wang H, Liang X, Ma J, Wang Y. Pathological and prognostic significance of hypoxia-inducible factor 1alpha expression in epithelial ovarian cancer: a meta-analysis. Tumour Biol. 2014; 35:8149-8159.

19. Loboda A, Jozkowicz A, Dulak J. HIF-1 and HIF2 transcription factors - similar but not identical. Mol Cells. 2010; 29:435-442.

20. Nakayama K. Cellular signal transduction of the hypoxia response. J Biochem. 2009; 146:757-765.

21. Semenza G. Signal transduction to hypoxia-inducible factor 1. Biochem Pharmacol. 2002; 64:993-998.

22. Dehne N, Fuhrmann D, Brune B. Hypoxia-inducible factor (HIF) in hormone signaling during health and disease. Cardiovasc Hematol Agents Med Chem. 2013; 11:125-135.

23. Lee J, Park SY, Lee EK, Park CG, Chung HC, Rha SY, Kim YK, Bae GU, Kim BK, Han JW, Lee HY. Activation of hypoxia-inducible factor-1alpha is necessary for lysophosphatidic acid-induced vascular endothelial growth factor expression. Clin Cancer Res. 2006; 12:6351-6358.

24. Lee SJ, No YR, Dang DT, Dang LH, Yang VW, Shim H, Yun CC. Regulation of hypoxia-inducible factor 1alpha (HIF-1alpha) by lysophosphatidic acid is dependent on interplay between p53 and Kruppel-like factor 5. J Biol Chem. 2013; 288:25244-25253.

25. Semenza GL. Targeting HIF-1 for cancer therapy. Nat Rev Cancer. 2003; 3:721-732.

26. Lu X, Kang Y. Hypoxia and hypoxia-inducible factors: master regulators of metastasis. Clin Cancer Res. 2010; 16:5928-5935.

27. Jiang J, Tang YL, Liang XH. EMT: a new vision of hypoxia promoting cancer progression. Cancer Biol Ther. 2011; 11:714-723. 
28. Kalluri R, Weinberg RA. The basics of epithelialmesenchymal transition. J Clin Invest. 2009; 119: 1420-1428.

29. De Craene B, Berx G. Regulatory networks defining EMT during cancer initiation and progression. Nat Rev Cancer. 2013; 13:97-110.

30. Zavadil J, Bottinger EP. TGF-beta and epithelial-tomesenchymal transitions. Oncogene. 2005; 24:5764-5774.

31. Ermakov A, Pells S, Freile P, Ganeva VV, Wildenhain J, Bradley M, Pawson A, Millar R, De Sousa PA. A role for intracellular calcium downstream of G-protein signaling in undifferentiated human embryonic stem cell culture. Stem Cell Res. 2012; 9:171-184.

32. Seo JH, Jeong KJ, Oh WJ, Sul HJ, Sohn JS, Kim YK, Cho do Y, Kang JK, Park CG, Lee HY. Lysophosphatidic acid induces STAT3 phosphorylation and ovarian cancer cell motility: their inhibition by curcumin. Cancer Lett. 2010; 288:50-56.

33. Rhee HJ, Nam JS, Sun Y, Kim MJ, Choi HK, Han DH, Kim NH, Huh SO. Lysophosphatidic acid stimulates cAMP accumulation and cAMP response element-binding protein phosphorylation in immortalized hippocampal progenitor cells. Neuroreport. 2006; 17:523-526.

34. Lee CW, Kim NH, Choi HK, Sun Y, Nam JS, Rhee HJ, Chun J, Huh SO. Lysophosphatidic acid-induced c-fos upregulation involves cyclic AMP response element-binding protein activated by mitogen- and stress-activated protein kinase-1. J Cell Biochem. 2008; 104:785-794.

35. Carroll VA, Ashcroft M. Role of hypoxia-inducible factor (HIF)-1alpha versus HIF-2alpha in the regulation of HIF target genes in response to hypoxia, insulin-like growth factor-I, or loss of von Hippel-Lindau function: implications for targeting the HIF pathway. Cancer Res. 2006; 66:6264-6270.

36. Joshi HP, Subramanian IV, Schnettler EK, Ghosh G, Rupaimoole R, Evans C, Saluja M, Jing Y, Cristina I, Roy S, Zeng Y, Shah VH, Sood AK, et al. Dynamin 2 along with microRNA-199a reciprocally regulate hypoxia-inducible factors and ovarian cancer metastasis. Proc Natl Acad Sci U S A. 2014; 111:5331-5336.

37. Radhika V, Onesime D, Ha JH, Dhanasekaran N. Galpha13 stimulates cell migration through cortactin-interacting protein Hax-1. J Biol Chem. 2004; 279:49406-49413.

38. Radhika V, Dhanasekaran N. Transforming G proteins. Oncogene. 2001; 20:1607-1614.

39. Bian D, Su S, Mahanivong C, Cheng RK, Han Q, Pan ZK, Sun P, Huang S. Lysophosphatidic Acid Stimulates Ovarian Cancer Cell Migration via a Ras-MEK Kinase 1 Pathway. Cancer Res. 2004; 64:4209-4217.

40. Needham LK, Rozengurt E. Galpha12 and Galpha13 stimulate Rho-dependent tyrosine phosphorylation of focal adhesion kinase, paxillin, and p130 Crk-associated substrate. J Biol Chem. 1998; 273:14626-14632.

41. Yuan J, Slice LW, Gu J, Rozengurt E. Cooperation of Gq, Gi, and G12/13 in protein kinase D activation and phosphorylation induced by lysophosphatidic acid. J Biol Chem. 2003; 278:4882-4891.

42. Tsai YP, Wu KJ. Hypoxia-regulated target genes implicated in tumor metastasis. J Biomed Sci. 2012; 19:102.

43. Tania M, Khan MA, Fu J. Epithelial to mesenchymal transition inducing transcription factors and metastatic cancer. Tumour Biol. 2014; 35:7335-7342.

44. Casas E, Kim J, Bendesky A, Ohno-Machado L, Wolfe CJ, Yang J. Snail2 is an essential mediator of Twist1-induced epithelial mesenchymal transition and metastasis. Cancer Res. 2011; 71:245-254.

45. Cheng JC, Klausen C, Leung PC. Hypoxia-inducible factor 1 alpha mediates epidermal growth factor-induced down-regulation of E-cadherin expression and cell invasion in human ovarian cancer cells. Cancer Lett. 2013; 329:197-206.

46. Storci G, Sansone P, Mari S, D’Uva G, Tavolari S, Guarnieri T, Taffurelli M, Ceccarelli C, Santini D, Chieco P, Marcu KB, Bonafe M. TNFalpha up-regulates SLUG via the NF-kappaB/HIF1alpha axis, which imparts breast cancer cells with a stem cell-like phenotype. J Cell Physiol. 2010; 225:682-691.

47. Zhang J, Cheng Q, Zhou Y, Wang Y, Chen X. Slug is a key mediator of hypoxia induced cadherin switch in HNSCC: correlations with poor prognosis. Oral Oncol. 2013; 49:1043-1050.

48. Chilov D, Camenisch G, Kvietikova I, Ziegler U, Gassmann M, Wenger RH. Induction and nuclear translocation of hypoxia-inducible factor-1 (HIF-1): heterodimerization with ARNT is not necessary for nuclear accumulation of HIF1alpha. J Cell Sci. 1999; 112:1203-1212.

49. Kim JY, Kim YM, Yang CH, Cho SK, Lee JW, Cho M. Functional regulation of Slug/Snail2 is dependent on GSK-3beta-mediated phosphorylation. FEBS J. 2012; 279:2929-2939.

50. Domcke S, Sinha R, Levine DA, Sander C, Schultz N. Evaluating cell lines as tumour models by comparison of genomic profiles. Nat Commun. 2013; 4:2126.

51. Mitra AK, Davis DA, Tomar S, Roy L, Gurler H, Xie J, Lantvit DD, Cardenas H, Fang F, Liu Y, Loughran E, Yang J, Sharon Stack M, et al. In vivo tumor growth of high-grade serous ovarian cancer cell lines. Gynecol Oncol. 2015; 138:372-377.

52. Kim KS, Sengupta S, Berk M, Kwak YG, Escobar PF, Belinson J, Mok SC, Xu Y. Hypoxia enhances lysophosphatidic acid responsiveness in ovarian cancer cells and lysophosphatidic acid induces ovarian tumor metastasis in vivo. Cancer Res. 2006; 66:7983-7990.

53. Karni R, Dor Y, Keshet E, Meyuhas O, Levitzki A. Activated pp60c-Src leads to elevated hypoxia-inducible factor (HIF)-1alpha expression under normoxia. J Biol Chem. 2002; 277:42919-42925.

54. Lee HY, Lee T, Lee N, Yang EG, Lee C, Lee J, Moon EY, Ha J, Park H. Src activates HIF-1alpha not through direct phosphorylation of HIF-1alpha specific prolyl-4 hydroxylase 
2 but through activation of the NADPH oxidase/Rac pathway. Carcinogenesis. 2011; 32:703-712.

55. Li QY, Zhu YF, Zhang M, Chen L, Zhang Z, Du YL, Ren GQ, Tang JM, Zhong MK, Shi XJ. Chlorogenic acid inhibits hypoxia-induced pulmonary artery smooth muscle cells proliferation via c-Src and Shc/Grb2/ERK2 signaling pathway. Eur J Pharmacol. 2015; 751:81-88.

56. Hanke JH, Gardner JP, Dow RL, Changelian PS, Brissette WH, Weringer EJ, Pollok BA, Connelly PA. Discovery of a novel, potent, and Src family-selective tyrosine kinase inhibitor. Study of Lck- and FynT-dependent T cell activation. J Biol Chem. 1996; 271:695-701.

57. Puttini M, Coluccia AM, Boschelli F, Cleris L, Marchesi E, Donella-Deana A, Ahmed S, Redaelli S, Piazza R, Magistroni V, Andreoni F, Scapozza L, Formelli F, et al. In vitro and in vivo activity of SKI-606, a novel Src-Abl inhibitor, against imatinib-resistant Bcr-Abl+ neoplastic cells. Cancer Res. 2006; 66:11314-11322.

58. Yang D, Sun Y, Hu L, Zheng H, Ji P, Pecot CV, Zhao Y, Reynolds S, Cheng H, Rupaimoole R, Cogdell D, Nykter M, Broaddus R, et al. Integrated analyses identify a master microRNA regulatory network for the mesenchymal subtype in serous ovarian cancer. Cancer Cell. 2013; 23:186-199.

59. Lamouille S, Xu J, Derynck R. Molecular mechanisms of epithelial-mesenchymal transition. Nat Rev Mol Cell Biol. 2014; 15:178-196.

60. Welsh S, Williams R, Kirkpatrick L, Paine-Murrieta G, Powis G. Antitumor activity and pharmacodynamic properties of PX-478, an inhibitor of hypoxia-inducible factor-1alpha. Mol Cancer Ther. 2004; 3:233-244.

61. Koh MY, Spivak-Kroizman T, Venturini S, Welsh S, Williams RR, Kirkpatrick DL, Powis G. Molecular mechanisms for the activity of PX-478, an antitumor inhibitor of the hypoxia-inducible factor-1alpha. Mol Cancer Ther. 2008; 7:90-100.

62. Yee Koh M, Spivak-Kroizman TR, Powis G. HIF1 regulation: not so easy come, easy go. Trends Biochem Sci. 2008; 33:526-534.

63. Yang $\mathrm{MH}, \mathrm{Wu} \mathrm{MZ}$, Chiou SH, Chen PM, Chang SY, Liu CJ, Teng SC, Wu KJ. Direct regulation of TWIST by HIF-1alpha promotes metastasis. Nat Cell Biol. 2008; 10:295-305.

64. Yang $\mathrm{MH}, \mathrm{Wu} \mathrm{KJ}$. TWIST activation by hypoxia inducible factor-1 (HIF-1): implications in metastasis and development. Cell Cycle. 2008; 7:2090-2096.
65. Imai T, Horiuchi A, Wang C, Oka K, Ohira S, Nikaido T, Konishi I. Hypoxia attenuates the expression of E-cadherin via up-regulation of SNAIL in ovarian carcinoma cells. Am J Pathol. 2003; 163:1437-1447.

66. Hajra KM, Chen DY, Fearon ER. The SLUG zinc-finger protein represses E-cadherin in breast cancer. Cancer Res. 2002; 62:1613-1618.

67. Bolos V, Peinado H, Perez-Moreno MA, Fraga MF, Esteller M, Cano A. The transcription factor Slug represses E-cadherin expression and induces epithelial to mesenchymal transitions: a comparison with Snail and E47 repressors. J Cell Sci. 2003; 116:499-511.

68. Raymond JR, Jr., Appleton KM, Pierce JY, Peterson YK. Suppression of GNAI2 message in ovarian cancer. J Ovarian Res. 2014; 7:6.

69. Burkhalter RJ, Westfall SD, Liu Y, Stack MS. Lysophosphatidic Acid Initiates Epithelial to Mesenchymal Transition and Induces beta-Catenin-mediated Transcription in Epithelial Ovarian Carcinoma. J Biol Chem. 2015; 290:22143-22154.

70. Palayoor ST, Mitchell JB, Cerna D, Degraff W, John-Aryankalayil M, Coleman CN. PX-478, an inhibitor of hypoxia-inducible factor-1alpha, enhances radiosensitivity of prostate carcinoma cells. Int J Cancer. 2008; 123:2430-2437.

71. Schwartz DL, Powis G, Thitai-Kumar A, He Y, Bankson J, Williams R, Lemos R, Oh J, Volgin A, Soghomonyan S, Nishii R, Alauddin M, Mukhopadhay U, et al. The selective hypoxia inducible factor-1 inhibitor PX-478 provides in vivo radiosensitization through tumor stromal effects. Mol Cancer Ther. 2009; 8:947-958.

72. Zhao T, Ren H, Jia L, Chen J, Xin W, Yan F, Li J, Wang X, Gao S, Qian D, Huang C, Hao J. Inhibition of HIF-1alpha by PX-478 enhances the anti-tumor effect of gemcitabine by inducing immunogenic cell death in pancreatic ductal adenocarcinoma. Oncotarget. 2015; 6:2250-2262. doi: 10.18632/oncotarget.2948.

73. Yu D, Wolf JK, Scanlon M, Price JE, Hung MC. Enhanced c-erbB-2/neu expression in human ovarian cancer cells correlates with more severe malignancy that can be suppressed by E1A. Cancer Res. 1993; 53:891-898.

74. Kumar RN, Ha JH, Radhakrishnan R, Dhanasekaran DN. Transactivation of platelet-derived growth factor receptor alpha by the GTPase-deficient activated mutant of Galpha12. Mol Cell Biol. 2006; 26:50-62. 